\title{
Influences of initial conditions and boundary conditions on regional and urban scale Eulerian air quality transport model simulations
}

\author{
Tsun-Hsien Liu ${ }^{\text {a,* }}$, Fu-Tien Jeng ${ }^{\text {a }}$, Ho-Chun Huang ${ }^{b}$, Erik Berge ${ }^{c}$, Julius \\ S. Chang ${ }^{b}$ \\ a Graduate Institute of Environmental Engineering, National Taiwan University, 71 Chou-Shan Road, Taipei 106, Taiwan, ROC \\ ${ }^{\mathrm{b}}$ Atmospheric Science Research Center, State University of New York at Albany, Albany, NY, USA \\ ${ }^{\mathrm{c}}$ Research and Development Division, Norwegian Meteorological Institute, Oslo, Norway
}

Received 26 October 1999; received in revised form 20 April 2000; accepted 5 June 2000

Importance of this Paper: Initial and boundary conditions can have influences on the calculated results of regional-and urban-scale Eulerian chemistry models. While most modeling studies have difficulties in knowing the initial and boundary influences, their resulted uncertainties are usually not discussed. This study quantified these influences through theoretical analysis of the governing equation and then verified the results by applying a three-dimensional air quality model.

\begin{abstract}
Influences of initial and boundary conditions were quantified by analysis of a simplified governing equation followed with a tracer and $\mathrm{O}_{3}$ simulations using a three-dimensional air quality transport model. The analytical solution derived from the governing equation indicated that the impacts of initial conditions on a given site decrease with simulation time and significantly affect the species concentrations before the arrival of the boundary conditions. Boundary influences, which decrease during the downwind transport, are significant to a selected site when the arrival time of boundary condition is short and the species lifetime is long.

Non-reactive tracers and $\mathrm{O}_{3}$ were then added to SARMAP Air Quality Model (SAQM), a three-dimensional transport model, and the results showed that tracer lifetime and arrival time determine the boundary influences on a given site consistent with the analysis obtained from the governing equation. Moreover, boundary conditions followed initial conditions to affect the calculated ozone concentrations at a given site and the influences are proportional to the magnitude of the prescribed boundary conditions, arrival time, and are more obvious at local nighttime. When the arrival time is $15 \mathrm{~h}$, an average of $64 \%$ of initial ozone boundary conditions will contribute to the calculated ozone concentrations. For arrival times of 23,20 , and $7 \mathrm{~h}$, the ratios are $26 \%, 34 \%$, and $79 \%$, respectively. This study indicated that the derived analytical solution could be used by air quality modelers in estimating the boundary influences as long as the species lifetime are known. () 2001 Elsevier Science Ltd. All rights reserved.
\end{abstract}

Keywords: Arrival time; Traveling time; Lifetime; SARMAP Air Quality Model (SAQM)

\section{Introduction}

${ }^{*}$ Corresponding author. Tel.: +886-2-23630231 ext. 3041; fax: +886-2-23626527.

E-mail address: liu@airlab.ntu.edu.tw (T.-H. Liu).
In regional- and urban-scale air quality models, initial and boundary conditions are usually required for performing simulations. The initial conditions are 


\begin{tabular}{|c|c|c|c|}
\hline \multicolumn{2}{|c|}{ Symbols } & $S$ & step function \\
\hline C & concentration level of chemical species & $u$ & wind speed \\
\hline$C_{0}$ & background concentration of chemical species & $x$ & distance to boundary \\
\hline$C_{\mathrm{B}}$ & $\begin{array}{l}\text { concentration level of chemical species speci- } \\
\text { fied as boundary condition }\end{array}$ & & $\begin{array}{l}\text { residence time of air in a box } \\
\text { lifetime of species }\end{array}$ \\
\hline$C_{\mathrm{I}}$ & $\begin{array}{l}\text { concentration level of chemical species speci- } \\
\text { fied as initial condition }\end{array}$ & $\tau_{\mathrm{B}}$ & $\begin{array}{l}\text { arrival time (traveling time) of boundary } \\
\text { condition }\end{array}$ \\
\hline$L$ & $\begin{array}{l}\text { loss rate of chemical species by chemical } \\
\text { reactions and deposition on surface }\end{array}$ & $\begin{array}{l}\Psi_{\mathrm{IC}} \\
\Psi_{\mathrm{BC}}\end{array}$ & $\begin{array}{l}\text { influence of initial condition } \\
\text { influence of boundary condition }\end{array}$ \\
\hline$P$ & $\begin{array}{l}\text { production (including emission) of chemical } \\
\text { species }\end{array}$ & $\Psi_{P / L}$ & influence of local characteristics \\
\hline
\end{tabular}

specified within the simulation domain at the beginning of simulation, while boundary conditions are prescribed throughout the simulation period. Ideally, initial and boundary conditions should be provided from observations. However, few observations were generally available (National Research Council, 1991). Three general methods were suggested by the National Research Council (1991) to specify initial and boundary conditions: (1) use the output of a larger domain simulation; (2) use objective or interpolated techniques when applying ambient observed data; (3) isolate simulation domain from significant emission sources. Since initial and boundary conditions are usually specified in some extent of presumption, it is important to minimize the influences of initial and boundary conditions in the model calculations. Berge et al. (2000) and Seinfeld and Pandis (1997) have indicated that the influence of initial conditions could be minimized through "start-up" run prior to formal simulations. However, the species evolution in the downwind area is continuously affected by upwind boundary conditions throughout this "start-up" process (Seinfeld and Pandis, 1997). Thus, Seinfeld and Pandis (1997) have suggested a few rules to reduce the influences of boundary conditions. First, include all the sources that have potential effects on the given region in the simulation domain. Second, include the sources implicitly in boundary conditions, and third, apply the simulation results of larger model domain to the boundary conditions of smaller nested simulation domains.

Although influences of boundary conditions can be significant, it can also be minor in some cases. Kuklin and Seinfeld (1995) have applied a photochemical airquality model that has been used in the California Institute of Technology to assess the sensitivity of the ozone carrying capacity due to different boundary conditions of reactive organic gases (ROGs) and $\mathrm{NO}_{x}$. By applying the model to the domain of South Coast Air Basin of California, they found that peak ozone concentrations are insensitive to the ROG boundary con- ditions at extremely low $\mathrm{NO}_{x}$ emissions. The ozone carrying capacity is sensitive to ROG boundary conditions only when $\mathrm{NO}_{x}$ emissions are high (Kuklin and Seinfeld, 1995).

Several efforts were implemented earlier to study the influences of initial and boundary conditions. Berge et al. (2000) have studied the importance of the initial concentrations on the calculated photochemical oxidants. A simple ordinary differential equation was derived to explore the influence of initial conditions in their study:

$\frac{\mathrm{d} C}{\mathrm{~d} t}=P-L C$,

where $C$ is the species concentration, $P$ the production including emission and $L$ is the related to the rate of species concentration removed by physical or chemical processes, e.g., chemical reactions and dry deposition, and its reciprocal is defined as the lifetime of the chemical species. The analytical solution of Eq. (1) can be derived if $P$ and $L$ are constants during the integration time or simulation period.

$C(t)=C_{\mathrm{I}} \mathrm{e}^{-L t}+\frac{P}{L}\left(1-\mathrm{e}^{-L t}\right)$,

where $C_{\mathrm{I}}$ is the initial condition. Eq. (2) indicates that the influences of initial conditions, $C_{\mathrm{I}} \mathrm{e}^{-L t}$, decrease exponentially with time while the influences of local characteristics $(P / L)$ increased with time. Eq. (2) also illustrates that the influences of initial conditions can be minimized after a "start-up" run, and the final results are dominated by local characteristics in model simulations.

Although Eq. (1) is a useful tool in understanding the effects of initial conditions, it neglects the influences of transport and boundary conditions. In the study of Seinfeld and Pandis (1997), the influences of transport and boundary conditions are included in an Eulerian box model: 
$\frac{\mathrm{d} C}{\mathrm{~d} t}=P-L C+\frac{C_{0}-C}{\tau_{\mathrm{r}}}$,

where $C, P$, and $L$ are the same as defined in Eq. (1). $\tau_{\mathrm{r}}$ is the residence time of air over the box area and $C_{0}$ is the background concentration, which represents the boundary condition in this model. The analytical solution of this equation, which is similar to Eq. (2), is as follows:

$$
\begin{aligned}
C(t)= & C_{\mathrm{I}} \mathrm{e}^{-\left(L+1 / \tau_{\mathrm{r}}\right) t}+\frac{P \tau_{\mathrm{r}}}{L \tau_{\mathrm{r}}+1}\left(1-\mathrm{e}^{-\left(L+1 / \tau_{\mathrm{r}}\right) t}\right) \\
& +\frac{C_{0}}{L \tau_{\mathrm{r}}+1}\left(1-\mathrm{e}^{-\left(L+1 / \tau_{\mathrm{r}}\right) t}\right) .
\end{aligned}
$$

In Eq. (4), influences of $C_{\mathrm{I}}$ decrease much faster than that in Eq. (2) due to the outward-transport of initial conditions. On the other hand, the outward-transport of local characteristics also reduces their influences. The influences of boundary conditions illustrated by the third term in Eq. (4) are proportional to the boundary concentrations and approach a maximum value, which is smaller than the original boundary conditions. Seinfeld and Pandis (1997) have indicated that the influence of boundary condition might be ignored if $C_{0}$ is much smaller than $P \tau_{\mathrm{r}}$. However, if the simulation box is enlarged to reduce the influence of boundary condition $\left(C_{0}\right)$ as suggested by Seinfeld and Pandis (1997), the effect of $P$ term will be diluted and $\tau_{\mathrm{r}}$ will be increased as a result, and the combined effect (the ratio of $C_{0}$ versus $\left.P \tau_{\mathrm{r}}\right)$ remains the same. That is, they are still of equivalent importance in Eq. (3).

The solutions of governing equations for most of the Eulerian air-quality models are hyperbolic and strongly coupled with initial and boundary conditions. Theoretically, initial and boundary conditions can affect solutions over simulation domain to a great extent. However, some previous studies on the influences of initial and boundary conditions on simulation results are usually qualitative (National Research Council, 1991; Seinfeld and Pandis, 1997). Very few studies quantified these influences. Thus, the goal of this study is to explore the influences of initial and boundary conditions systematically and attempt to quantify their influences.

\section{Methodology}

Three different approaches were applied in this study in order to understand the effects of initial and boundary conditions. First of all, an analytical solution of a governing equation was used to illuminate the general concept of the influences of initial and boundary conditions on model calculations. In addition, the analytical solution was examined by applying a three-dimensional model. A non-reactive tracer is added to this threedimensional Eulerian transport model modified from
SAQM. Moreover, ozone concentrations are calculated using the same three-dimensional transport model with Carbon Bond Mechanism version 4 (CBM4). A more realistic behavior of a degradable transported chemical species can be seen through using the complicated threedimensional transport model. With these approaches, a general rule of how to quantify the influence of boundary condition can be obtained.

\subsection{Analytical solution of a simplified governing equation}

A simplified one-dimensional transport equation was derived for a basic analysis of the influences of initial conditions, boundary conditions, and local characteristics of chemical species. The governing equation is a first-order partial differential equation as follows,

$\frac{\partial C}{\partial t}+\frac{\partial(u C)}{\partial x}=P-L C$,

where $C$ is the concentration of the chemical species, $u$ the wind speed in $x$ direction, $P$ the production term including emission, and $L$ is the loss term including the surface deposition. The above equation is similar to Eq. (1) except that a transport term was added. Since diffusion in the direction of advection can be neglected, the diffusion term is removed from the equation for simplification. If $u, P$, and $L$ are constants, Eq. (5) can be reduced to a first-order linear partial differential equation and solved as,

$$
\begin{aligned}
C(x, t)= & C_{\mathrm{B}} \mathrm{e}^{-L x / u} S_{x / u}(t)+C_{\mathrm{I}} \mathrm{e}^{-L t}\left(1-S_{x / u}(t)\right) \\
& +\frac{P}{L}\left[1-\mathrm{e}^{-L t}+\left(\mathrm{e}^{-L t}-\mathrm{e}^{-L x / u}\right) S_{x / u}(t)\right],
\end{aligned}
$$

where $S_{x / u}(t)$ is a step function as

$$
\begin{array}{ll}
S_{x / u}(t)=0 & \text { if } t<x / u, \\
S_{x / u}(t)=1 & \text { if } t \geqslant x / u .
\end{array}
$$

$C_{\mathrm{B}}$ and $C_{\mathrm{I}}$ in Eq. (6) are the boundary and initial conditions, respectively and $x$ is the distance between the interested site and the boundaries. The first three terms in Eq. (6) represent the influences of boundary conditions, initial conditions, and local characteristic on species evolutions at a given site.

Two calculations using Eq. (6) were conducted to demonstrate the analytical solution. Initial conditions, boundary conditions, and local characteristic features (hereafter denoted as $P / L$ ) for both calculations were all assigned to be $20 \mathrm{ppb}$, which is typical for $\mathrm{NO}_{x}$ in urban area. Lifetimes of simulated species were assigned to be $48 \mathrm{~h}$, which is approximately the same as the lifetime of $\mathrm{NO}_{x}$ in the lower troposphere (Seinfeld and Pandis, 1997). The only difference between these two calculations was the distance from the interested sites to the boundary. Assuming the wind speed to be constant, the traveling times of air parcel from the boundary to 
the selected sites were assigned to be 48 and $12 \mathrm{~h}$ for the first and second calculations, respectively. The traveling time, which is defined as the time for an air parcel traveling from the boundary to an interested site, is also called arrival time.

\subsection{Tracer simulations using three-dimensional transport model}

In this approach, degradable tracers were added to the SAQM in order to study the effects of boundary conditions. SAQM is a three-dimensional comprehensive Eulerian model that solves coupled transportchemistry processes (Chang et al., 1997; Dabdub et al., 1997). It is developed to study the ozone pollution problem in the San Joaquin Valley Air Basin and the surrounding regions in California (Thuillier and Ranzieri, 1993) and to provide a basis for the planning of regional air quality control strategies. Module of chemical reactions was turned off for these simulations, because only the general behavior of tracer is interested in this approach.

Meteorology data employed for these simulations are obtained from the output of Mesoscale Meteorology Model version 5 released by PENN State/NCAR (Seaman et al., 1995). The simulation period starting from 2 to 7 August 1990 is a high ozone episode. The prevailing wind of this episode is basically from the west according to our analysis on the wind field.

Two cases were performed in these tracer simulations. The first case varies the tracer lifetimes and the second case varied the traveling time, while other variables in the simulation remain the same. For the first case study, 4 lifetimes, 6, 12, 24, and $48 \mathrm{~h}$, are assigned to tracers. For the second case, four sites as illustrated in Fig. 1 were selected for comparison. Despite these sites having different local sensitivities to $\mathrm{NO}_{x}$ or ROG emissions (Lu, 1998; Berge et al., 2000), their distances from the western boundary are far more important as a role in the results. Both initial and western boundary conditions are assigned to be $100 \mathrm{ppb}$ in the two case studies. Though tracer simulations are performed without the chemical module, tracer concentrations still evolve with time according to the prescribed lifetime. From these simulations, the basic features of evolution of degradable species affected by the initial and boundary conditions in a three-dimensional transport model will be obtained.

\subsection{Ozone simulation using three-dimensional transport model}

Chemistry module in SAQM was turned on in these ozone simulations to study the influence of boundary conditions. The chemistry mechanism applied to the SAQM is CBM4, which is slightly modified from a

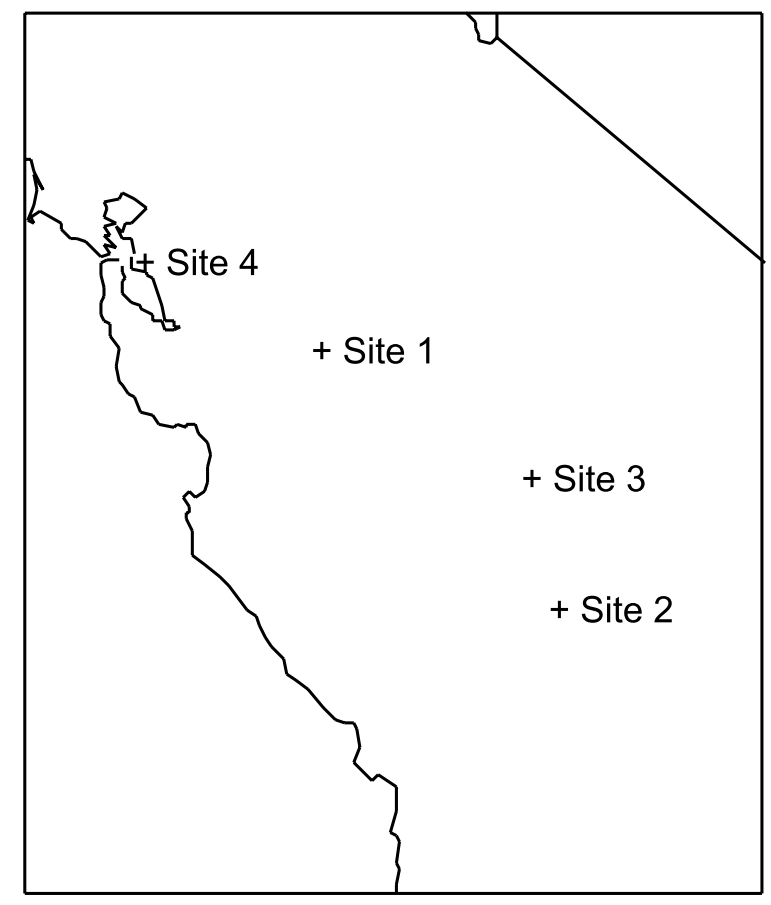

Fig. 1. Simulation domain and interested sites for analysis (San Joaquin Valley of California).

previous version by Gery et al. (1989). More descriptions of the modified version could be found in Chang et al. (1997).

Three case studies with different western boundary conditions were performed to explore the influences of boundary condition on ozone concentrations. These three cases used the same initial conditions, meteorology data, emission data, and photolysis rates for a high ozone episode described by Chang et al. (1997), except that the three western boundary conditions of ozone concentrations in this study are assigned to be 25,0 , and $50 \mathrm{ppb}$. The 25-ppb ozone concentration applied in this study is obtained from averaged clean boundary conditions used for normal model simulations. The simulation episode starts at local time 4:00 am for all the three case studies.

\section{Results and discussion}

\subsection{Analytical solution analysis}

Two calculations illustrating the three terms in Eq. (6) evolving with time were shown in Figs. 2(a) and (b). In Fig. 2(a), the arrival time of boundary condition was $48 \mathrm{~h}$. The site started to show the influence of the boundary condition after $48 \mathrm{~h}$ of simulations. Since the air traveling time from boundary was constant (wind 


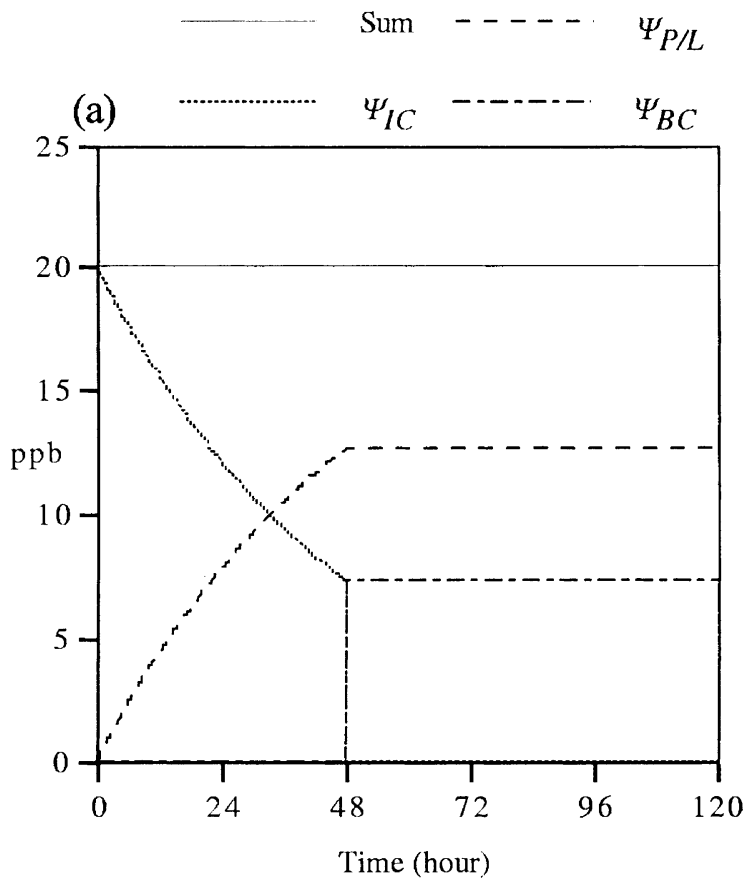

(b)

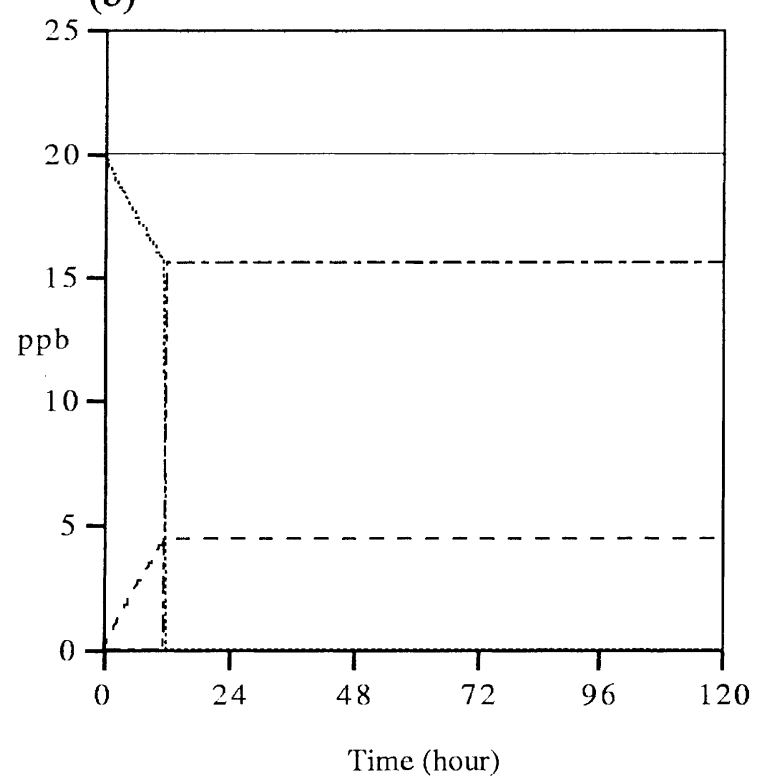

Fig. 2. Time series of influence of production/loss $(P / L)$, initial condition (IC), and boundary condition (BC) simulated by applying Eq. (6). Arrival time of $\mathrm{BC}$ is $48 \mathrm{~h}$ for (a) and $12 \mathrm{~h}$ for (b). Lifetime of simulated species is $48 \mathrm{~h}$ for both cases.

speed was constant), the degree of influence of boundary condition (denoted as $\Psi_{\mathrm{BC}}$ ) remained constant and can be calculated using Eq. (7). The influence of boundary condition was zero in the first $48 \mathrm{~h}$ and then jumped to
$7.4 \mathrm{ppb}$, which was $37 \%$ of the original boundary concentration. It also accounted for $37 \%$ of the total concentration level.

$\Psi_{\mathrm{BC}}=C_{\mathrm{B}} \mathrm{e}^{-L X / u} S_{x / u}(t)$.

In comparison with the influence of boundary condition, the influence of initial condition decayed exponentially and dropped to zero at the same time when boundary condition began to affect the site. It was because that at the time when the air parcel from boundary arrives, all air parcels originally located between the boundary and the selected site have passed through. Therefore, there was no residual of initial condition to be detected at the selected site. The influence of $P / L$ at this site increased from the beginning of simulation and reaches a maximum of $12.6 \mathrm{ppb}$. The impact due to the term $P / L$ is a combination of local characteristics at all upwind sites.

Fig. 2(b) indicated that the site started to show the influence of the boundary condition after $12 \mathrm{~h}$ of simulations. Because the site was closer to the boundary along with the same species lifetime, the influence of initial condition and boundary condition were larger than those found in the previous case. The influence of boundary condition reached $15.6 \mathrm{ppb}$, which was $78 \%$ of the original boundary concentration. Influences of initial condition diminished to zero after $12 \mathrm{~h}$ when the air parcel from boundary arrived. Due to shorter lifetime and shorter time for the air parcel to reside over the traveling path, the influence of local characteristics, $P / L$, was weaker than in Fig. 2(a).

Figs. 2(a) and (b) indicated that the influences of initial condition, boundary condition, and local characteristics on a given site mainly depended on the distance from its upwind boundary and the lifetime of interested species (Eq. (6)). The influence of boundary condition is significant if the distance to the boundary is small and the lifetime of species is long. The influence of initial condition is not negligible when the species lifetime is long and the simulation period is short. The local characteristics dominated in the calculation results only when the selected site is far from boundaries and the simulated species have a long lifetime.

It is also noted here that if the interested species has a long lifetime, the influence of initial conditions can still remain significant when the air parcel from the boundary arrives. In this case, a longer start-up run can introduce influences of boundary conditions on the sites far away from the boundary. In contrast, the influence of initial condition can be neglected when the lifetime of the given species is short. Therefore, the start-up run helps to reduce the influence of initial condition, but it also introduces the influence of boundary condition for species with longer lifetime. This is especially true for 
upper troposphere because the lifetimes of chemical species there are usually long (Berge et al., 2000).

\subsection{Tracer simulations using three-dimensional transport model}

Influence of boundary condition on the calculated results of a three-dimensional transport model was illustrated in Figs. 3 and 4. Fig. 3 demonstrated the influence of boundary condition when species lifetimes were varied. Site 1 in Fig. 1 was selected for this case study, and the averaged arrival time of air parcel from the boundary was about $15 \mathrm{~h}$. Since the arrival time was the same, impacts of the boundary conditions depended only on the lifetime of simulated species. The influence of boundary condition was zero at the beginning and started to affect the site $15 \mathrm{~h}$ later as the concentration jumped to a higher level as obtained from Eq. (7). They were 8.3, 28.7, 53.5, and $73.2 \mathrm{ppb}$ for species lifetimes of $6,12,24$, and $48 \mathrm{~h}$, respectively. This result was consistent with the findings obtained from the analytical solution in Section 3.1 which indicate that impacts of boundary condition were large for a long lifetime species. It is suggested that conclusions obtained from an analytical solution are applicable to tracer simulations of a three-dimensional transport model.

In Fig. 4, the arrival time of boundary conditions varied with the selected sites as shown in Fig. 1 depending on their distance to the boundary. The arrival times of boundary conditions were 15, 23, 20, and $7 \mathrm{~h}$ for Sites 1-4, respectively. With the same tracer lifetime, longer arrival time of boundary condition allows more time for simulated tracers to decay further during the transport processes and results in a weaker influence of boundary conditions. The corresponding values calculated from Eq. (7) were 73.2, 61.9, 65.9, and 86.4 ppb for

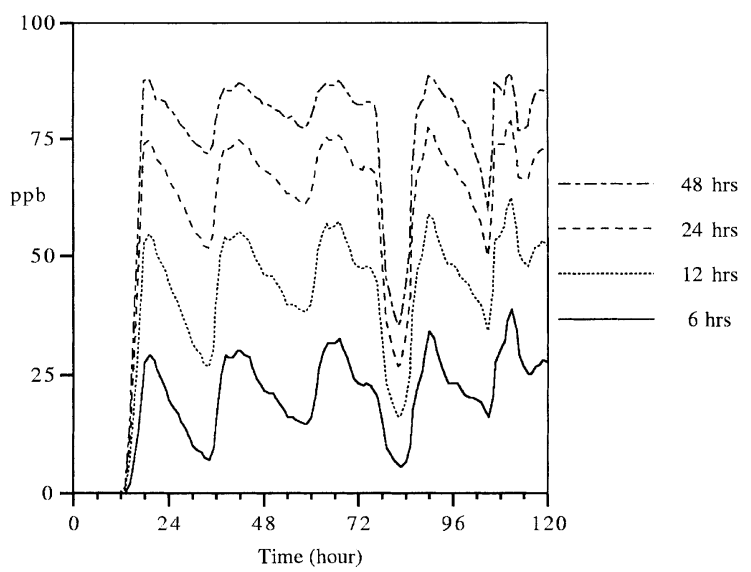

Fig. 3. Time series of influence of $\mathrm{BC}$ on Site 1 simulated by SAQM with different lifetimes of tracers.

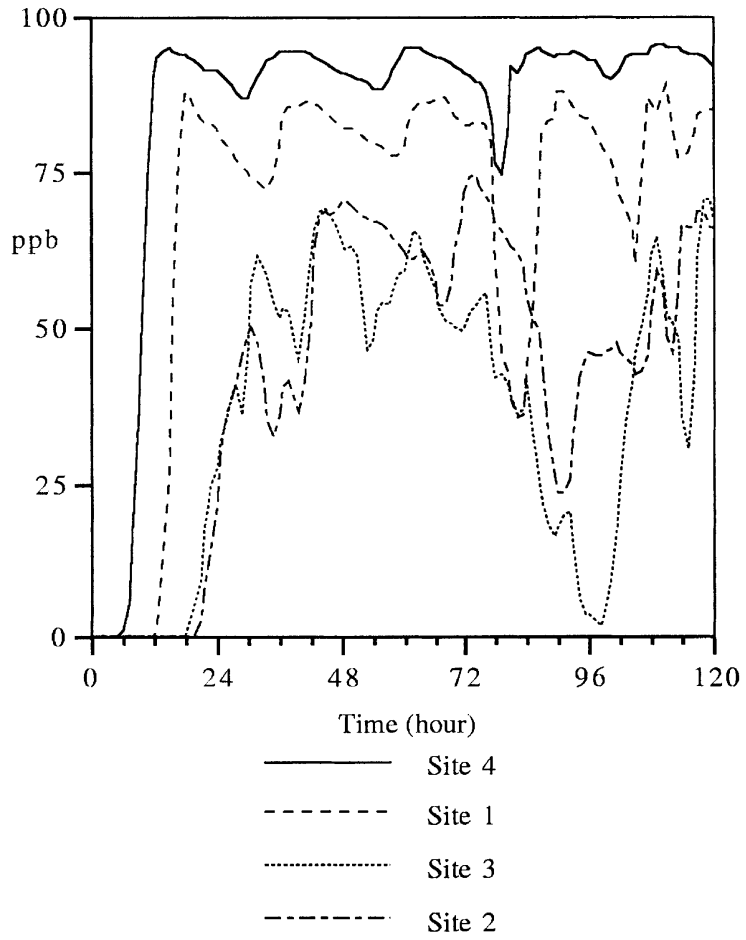

Fig. 4. Time series of influence of $\mathrm{BC}$ on different sites simulated by SAQM. Lifetime of simulated tracer is $48 \mathrm{~h}$.

Sites $1-4$, respectively. This result agreed well with the analysis obtained from the previous analytical solution.

Unlike in Figs. 2(a) and (b), 3 and 4 showed the impacts of boundary conditions fluctuating with time during the simulation period. The fluctuations were caused by the actual wind field, which did not flow constantly from one direction even though the prevailing wind was from the west. Different heights of mixed layer between day and night also lead to a fluctuated concentration. In Fig. 3, a rapid decrease of the influence of boundary condition could be found at the model hour 82 for Site 1 and a similar feature is also shown in Fig. 4 at almost the same time. After examining the wind fields, it was found that this minimum influence of boundary condition was caused by stronger advection and turbulent mixing in different directions. Despite the fluctuation shown, results of these tracer simulations are consistent with Eq. (7).

\subsection{Ozone simulations using three-dimensional air quality model}

The impacts of boundary conditions on the calculated ozone concentrations obtained from SAQM with CBM4 chemistry mechanisms are discussed in this section. The time series of ozone concentrations calculated for the four geographical sites, Sites 1-4 respectively, 
were shown in Figs. 5(a)-(d). The Curve 1-3 in each figure obtained from the three case studies indicates the time series of calculated ozone concentrations using the western boundary conditions of 25,0 , and $50 \mathrm{ppb}$, respectively.

Figs. 5(a)-(d) demonstrated that the calculated $\mathrm{O}_{3}$ concentrations varied with simulation time, when the concentrations peaked at daytime and decreased at nighttime. Of all the three cases, the calculated $\mathrm{O}_{3}$ concentrations were the same during the first several hours, although the concentrations varied from site to site. The calculated $\mathrm{O}_{3}$ concentrations for the three cases differed only after the arrival time (denoted as $\tau_{\mathrm{B}}$ hereafter) of the western boundary conditions, which was about 15,23 , 20, and $7 \mathrm{~h}$ for Site 1 to 4 , respectively. Before the arrival of the boundary conditions, the net contributions of the upwind initial conditions, upwind characteristics, and

(a)

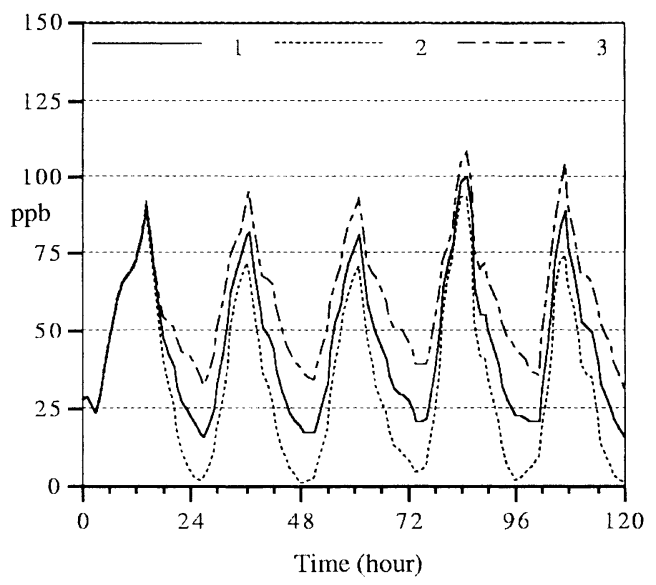

(c)

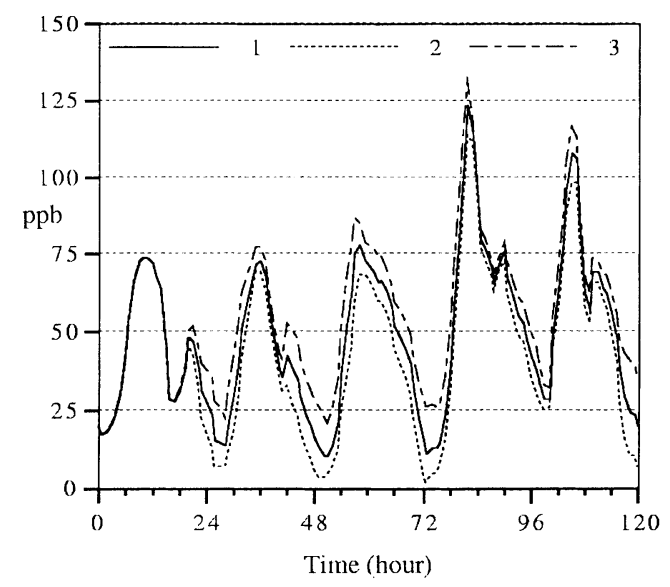

local characteristics were the same in the three cases and resulted in the same $\mathrm{O}_{3}$ concentrations.

When the boundary conditions arrived at each site, the boundary conditions began to affect the $\mathrm{O}_{3}$ concentrations at each site. Since then, $\mathrm{O}_{3}$ concentrations at each site were the net effects of all the upwind and local characteristics and boundary conditions, which resulted in the different concentrations between the three case studies. Figs. 5(a)-(d) showed that with $50 \mathrm{ppb}$ of western boundary condition, $\mathrm{O}_{3}$ concentrations are higher than those of the other cases for all the sites. At local nighttime, when the contributions of local $\mathrm{O}_{3}$ production and loss term were small, the $\mathrm{O}_{3}$ concentrations in the three cases demonstrated a greater discrepancy than in the daytime.

Since the western boundary conditions were assigned to be zero for Curve 2, the $\mathrm{O}_{3}$ concentrations after $\tau_{\mathrm{B}}$

(b)

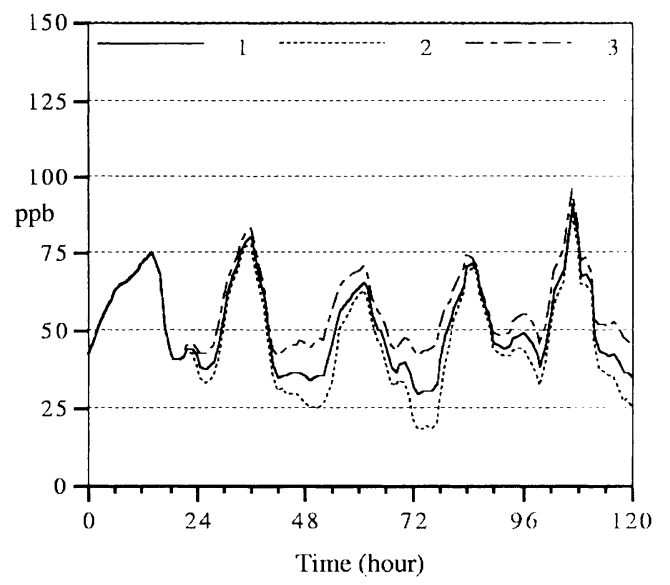

(d)

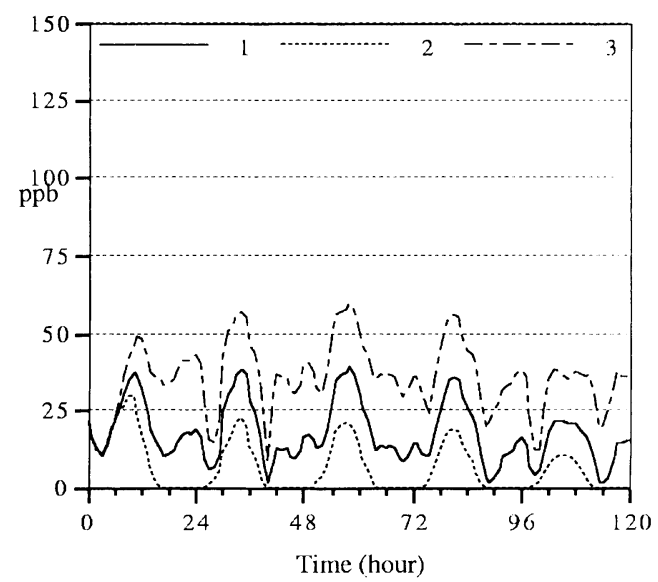

Fig. 5. Time series of ozone concentration for Sites 1 to 4 ((a)-(d)) with different BC conditions. Curve 1 represents the simulation result when western ozone $\mathrm{BC}=25 \mathrm{ppb}$. Curve 2 is $\mathrm{BC}=0 \mathrm{ppb}$. Curve 3 is $\mathrm{BC}=50 \mathrm{ppb}$. 
Table 1

Arrival time of boundary condition and averaged difference between simulations

\begin{tabular}{llllll}
\hline & Arrival time $\tau_{\mathrm{B}}(\mathrm{h})$ & \multicolumn{2}{c}{ Averaged difference after $\tau_{\mathrm{B}}(\mathrm{ppb})$} & \multirow{2}{*}{ Percentage to original BC (\%) } \\
\cline { 3 - 5 } & & Curves 1 and 2 & Curves 1 and 3 & Overall & \\
\hline Site 1 & 15 & 15.3 & 16.7 & 16.0 & 64 \\
Site 2 & 23 & 6.0 & 7.2 & 6.6 & 26 \\
Site 3 & 20 & 8.0 & 9.3 & 8.6 & 34 \\
Site 4 & 7 & $-^{\mathrm{a}}$ & 19.7 & 19.7 & 79 \\
\hline
\end{tabular}

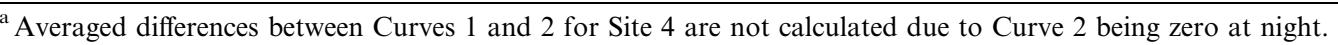

were contributed from the local characteristics and the upwind characteristics. As a result, the influence of boundary conditions $\left(\Psi_{\mathrm{BC}}\right)$ could be quantified by subtracting the ozone concentrations between Curves 1 and 2. Table 1 listed the difference of calculated ozone concentrations between Curve 2 and other curves averaged over the simulation period for each site. The different ozone concentrations shown were the influence of boundary conditions, which is a function of the arrival time of boundary conditions as demonstrated by Eq. (7). For site near the boundary, $\tau_{\mathrm{B}}$ was small and the influence of boundary condition was greater as indicated by Eq. (7). As expected, different $\mathrm{O}_{3}$ concentrations between case 2 and other cases in Site 4 (Fig. 5(d)) were $19.7 \mathrm{ppb}$ in average which were greater than those of other sites, for example, that of Site 2 was 6.6 ppb because it was the farthest site from the western boundary.

Fig. 5(d) also demonstrated that if the arrival time of boundary conditions is very small, then the $\mathrm{O}_{3}$ concentrations were significantly affected by the value of boundary conditions, and thus the discrepancies of $\mathrm{O}_{3}$ concentrations between case 2 and other cases remained almost the same for day- and nighttimes. When the arrival time of boundary condition was large, influences of initial and boundary conditions were greatly reduced due to the decaying effects, and the calculated $\mathrm{O}_{3}$ concentrations were mainly contributed by the local and upwind characteristics as shown in Figs. 5(b) and (c). The averaged difference of $\mathrm{O}_{3}$ concentrations between curves for Sites 2 and 3 were only 6.6 and 8.6 ppb, which were caused by $26 \%$ and $34 \%$ of original boundary condition. The averaged contribution to the total concentration was $64 \%$ of original boundary condition at Site 1, while that for Site 4 was $79 \%$. As a result, if the ozone boundary conditions are over- or underestimated by $10 \mathrm{ppb}$, after the downwind transport, influences of this error remaining at Site 1 is $6.4 \mathrm{ppb}$, Site 2 is $2.6 \mathrm{ppb}$, Site 3 is $3.4 \mathrm{ppb}$, and Site 4 is $7.9 \mathrm{ppb}$.

Influence of boundary conditions can be estimated by Eq. (7). If the lifetime of ozone $(\tau)$ is available in this area, it is feasible to estimate the influence of boundary condition. Since the lifetime of ozone in urban area is not available in this case, a trial of estimating the lifetime of ozone is also proposed in this study. Table 1 shows that the averaged $\mathrm{O}_{3}$ concentration differences,
Table 2

Estimated lifetime of ozone

\begin{tabular}{lll}
\hline & Arrival time $\tau_{\mathrm{B}}(\mathrm{h})$ & Lifetime $\tau(\mathrm{h})$ \\
\hline Site 1 & 15 & 33.5 \\
Site 2 & 23 & 17.3 \\
Site 3 & 20 & 18.8 \\
Site 4 & 7 & 29.8 \\
Average & & 25 \\
\hline
\end{tabular}

which are almost contributed from the decaying boundary influence, are functions of lifetime, arrival time and original boundary conditions $\left(C_{\mathrm{B}}\right)$. Therefore, Eq. (7) can be employed to estimate the local averaged ozone lifetime within a modeling domain as long as the above terms are known. By applying the averaged ozone difference and the $\tau_{\mathrm{B}}$ shown in Table 1, and the original boundary conditions of each case, the lifetime of $\mathrm{O}_{3}$ is calculated as shown in Table 2. Table 2 shows that lifetime of ozone at Site 1 is about $33.5 \mathrm{~h}$ and at Site 2 to Site 4 are 17.3, 18.8, and $29.8 \mathrm{~h}$, respectively. Therefore, the averaged ozone lifetime can be roughly estimated by applying Eq. (7). In this study, the averaged ozone lifetime calculated for this region is about $25 \mathrm{~h}$.

\section{Summary}

The derived solution, Eq. (6), from the simplified one-dimensional governing equation indicated that the influences of initial conditions basically depend on species lifetime. The influence of boundary conditions, on the other hand, depends on the lifetime of species and arrival time of boundary condition. In addition, the influences of initial conditions disappear after the arrival of boundary conditions. Therefore, influences of boundary conditions are more important for area near domain boundaries.

Further studies using three-dimensional transport model indicated that if the ozone boundary conditions are inaccurate, the error generated within the model domain can be estimated from Eq. (7). That is, if ozone concentration is over- or underestimated by $10 \mathrm{ppb}$, the resulting error for Site 1 is $6.4 \mathrm{ppb}$, Site 2 is $2.6 \mathrm{ppb}$, Site 3 is $3.4 \mathrm{ppb}$, and Site 4 is $7.9 \mathrm{ppb}$, depending on the 
arrival time of the boundary conditions. This error is greater for sites near the boundaries.

Since the influences of initial and boundary conditions may play an important role in Eulerian model simulations, it is suggested to minimize the influences of initial and boundary conditions and maximize those of local characteristics as proposed by National Research Council (1991) and Seinfeld and Pandis (1997). However, it is still important to assess the influence of initial and boundary conditions before any simulation results are interpreted.

\section{References}

Berge, E., Huang, H.-C., Chang, J.S., Liu, T.-H., 2000. A study of the importance of initial conditions for photochemical oxidant modeling. J. Geophys. Res., accepted.

Chang, J.S., Jin, S., Li, Y., Beauharnois, M., Lu, C.-H., Huang, H.-C., Tanrikulu, S., DaMassa, J., 1997. The SARMAP Air Quality Model: Final report. California Air Resources Board.

Dabdub, D., DeHaan, L.L., Kumar, N., Lurmann, F., Seinfeld, J.H., 1997. Computationally Efficient Acid Deposition Model for California. California Air Resource Board.
Gery, C.W., Whitten, G.Z., Killus, J.P., Dodge, M.C., 1989. A photochemical kinetics mechanism for urban and regional scale computer modeling. J. Geophy. Res. 94, 1292512956.

Kuklin, A., Seinfeld, J.H., 1995. Emission reductions needed to meet the standard for ozone in Southern California: effect of boundary condition. JAWMA 45, 899-901.

Lu, C.-H., 1998. Regional-scale oxidant formation: analysis of rural and urban coupling. Ph.D. Thesis, State University of New York at Albany, State University of New York at Albany, Albany, NY.

National Research Council, 1991. Rethinking the Ozone Problem in Urban and Regional Air Pollution. National Academy Press, Washington, DC.

Seaman, N.L., Stauffer, D.R., Lario-gibbs, A.M., 1995. A multiscale four-dimensional data assimilation system applied to the San Joaquin Valley during SARMAP. Part 1: Modeling design and basic performance characteristics. J. Appl. Meteor. 34, 1739-1761.

Seinfeld, J.H., Pandis, S.N., 1997. Atmospheric Chemistry and Physics: from Air pollution to Climate Change. Wiley, New York.

Thuillier, R.H., Ranzieri, A., 1993. SARMAP - lessons learned. In: Proceedings of the Transactions of Air and Waste Management Association Specialty Conference on Regional Photochemical Measurement and Modeling Studies, San Diego, California, 8-12 November. 